\title{
Liner shipping connectivity as determinant of trade
}

\author{
Marco Fugazza ${ }^{1 *}$ (D) and Jan Hoffmann ${ }^{2}$
}

\author{
* Correspondence: \\ marco.fugazza@unctad.org \\ ${ }^{1}$ Division on International Trade, \\ UNCTAD, Palais des Nations, \\ Geneva, Switzerland \\ Full list of author information is \\ available at the end of the article
}

\begin{abstract}
Transport connectivity is a crucial determinant of bilateral exports. This paper presents an empirical assessment of the relationship between bilateral maritime liner shipping connectivity and exports in containerizable goods during the period 2006-2013.

Making use of probed "gravity" type trade models, the paper incorporates new data on different measurements of maritime distance, as well as a unique new dataset and new bilateral connectivity indices developed by UNCTAD. The empirical investigations unequivocally show that lacking a direct maritime connection with a trade partner is associated with lower values of exports; any additional transshipment is associated with a $40 \%$ lower value of bilateral exports. Other indicators of liner shipping connectivity incorporated in the research take into consideration levels of competition and container vessel sizes. Results also indicate that the quality of bilateral connectivity as measured by several composite indices is a crucial determinant of bilateral exports. All empirical results suggest that in the absence of a bilateral connectivity indicator the impact of distance on bilateral exports in classical gravity models is likely to be overestimated.
\end{abstract}

Keywords: Liner shipping bilateral connectivity, Exports of containerizable goods, Container shipping networks, Gravity models

\section{Introduction}

Maritime transport is at the core of international trade in merchandises. Around 80\% of volume of goods exchanged in the world are transported via sea (UNCTAD 2008). The percentage share is even higher for most developing countries and in terms of total transport services measures in ton-kms.

The predominance of maritime transport has increased in particular for manufactured goods due to the intensification of containerized transport services. Thanks to containerization and the global liner shipping network, small and large exporters and importers of finished and intermediate containerizable goods from far away countries can trade with each-other, even if their individual trade transaction would not economically justify chartering a ship. Thanks to a network of regular container shipping services with transhipment operations in so-called hub ports, basically all countries are today connected to each other. A recent empirical study confirmed the "[e]ffects of the Container Revolution on World Trade" (Bernhofen et al. 2013). As far as North-North trade is concerned the authors found a cumulative (concurrent plus lag effects) average treatment effect of containerization over a 20 year time period amount to $790 \%$. The

(c) The Author(s). 2017 Open Access This article is distributed under the terms of the Creative Commons Attribution 4.0 International License (http://creativecommons.org/licenses/by/4.0/), which permits unrestricted use, distribution, and reproduction in any medium, provided you give appropriate credit to the original author(s) and the source, provide a link to the Creative Commons license, and indicate if changes were made. 
cumulative effect of bilateral GATT membership is found to raise trade by an average of $285 \%$, which is less than half the cumulative effect of full containerization.

Between 1970 and 2010, developing countries' share in the volume of seaborne exports rose from just 18 to $56 \%$ of the world's total (UNCTAD 2014). Despite this growing participation of developing countries in seaborne trade, evidence on maritime connections suggests that, except for few of them such as China, they may have not reached their full potential. Fugazza et al. (2013) find that the average number of direct maritime connections, meaning without involving any transhipment of the transported goods between the country of origin and their destination, is half for developing countries than what it is for developed ones.

Recent literature has emphasized the importance of transport costs and infrastructure in explaining trade and access to international markets. Based on the estimation of a gravity model using US data, Anderson and van Wincoop (2003) found that transport costs correspond to an average ad valorem tax equivalent of $21 \%$. These $21 \%$ include both directly measured freight costs and a $9 \%$ tax equivalent of the time value of goods in transit. Using a similar empirical approach, (Clark et al. 2004) estimates reveal that for most Latin American countries, transport costs are a greater barrier to U.S. markets than import tariffs. Sánchez et al. (2003) find that port efficiency is an important determinant of shipping costs (Arvis et al. 2013). Results obtained for a sample 178 countries over the 1995-2010 period indicate that maritime transport connectivity and logistics performance are very important determinants of bilateral trade costs. UNCTAD's Liner Shipping Connectivity Index (LSCI) and the World Bank's Logistics Performance Index (LPI) are together a more important source of variation in trade costs than geographical distance, and the effect is particularly strong for trade relations involving the South. Recent research has examined various aspects of maritime connectivity. Kumar and Hoffmann, (2002), Marquez Ramos et al., (2007), Wilmsmeier and Martínez-Zarzoso, (2010), Wilmsmeier and Hoffmann (2008) and Wilmsmeier et al., (31) incorporate measures of "connectivity" into research on maritime transport costs. Wilmsmeier (2014) analyses the effect of liner shipping network conditions on transport costs from different regions to South America. He also shows a decreasing effect of maritime services supply on transport cost and investigates to what extent the structure of the deployed fleet for directly connected regions contributes to the level of transport costs. Asturias and Petty (2012) conclude that distance becomes statistically insignificant in a trade model when two ports are connected by a direct liner shipping service. Angeloudis et al., (2006) and Bichou, (2004) look at connectivity in the context of maritime security. McCalla et al., (2005) measure intermediacy and connectivity for Caribbean shipping networks and (Notteboom, 2006b) for seaport systems. Notteboom, (2006a) also investigates the time factor in liner shipping services. Kosowska-Stamirowska et al. (2016) provide an historical analysis of topological changes of the maritime trade network and how they translate into navigability properties of this network based on the Lloyd's Shipping Index.

Another still burgeoning strand of the trade literature has attempted to assess the impact of maritime connectivity on bilateral exports (Wilmsmeier and Hoffmann 2008). Findings based on a sample of 189 freight rates of one company for the Caribbean show that trade routes with only indirect services (i.e., including transhipments) induce higher transport costs. Their estimates suggest that transhipment has the equivalent impact on freight rates as an increase in distance between two countries of $2612 \mathrm{~km}$ 
(Helble 2014, p. 2). Using a gravity model approach based on exports data of the 14 Pacific developing member countries of the Asian Development Bank for the time period 2011-2013 find that a direct shipping connection more than doubles trade in goods imports (Fugazza 2015). Using a gravity model approach based on a novel dataset on maritime connections for a sample of 178 countries collected over the 2006-2012 period finds that the absence of a direct connection is associated with a drop in exports value varying between 42 and $55 \%$.

Analytical contributions, including those cited previously, dealing with the assessment of transport costs components or with the assessment of connectivity on bilateral exports are based on either single dimension indicators, such as the existence or not a direct maritime connection, or on bilateral indicators of connectivity constructed using unilateral measures of the later and as such lacking a true bilateral nature. Hoffmann et al. (2014) first propose a truly bilateral index of liner shipping connectivity, the Liner Shipping Bilateral Connectivity Index (LSBCI). Their LSBCI is an extension of UNCTAD's already existing country-level Liner Shipping Connectivity Index (LSCI) (UNCTAD STAT, n.d.) based on a proper bilateralization transformation. Computation of the index for the year 2010 reveals that the top 100 LSBCIs are found on connections between 23 countries and that the top $250 \mathrm{LSBCIs}$ are found on connections between 41 countries. The highest LSBCI values are obtained for intra-regional routes, notably intra-Europa and intra-Asia. Several Asia-Europe connections are also among the top 20.

This paper builds on (Fugazza 2015) and (Hoffmann et al. 2014). It contributes to both the literature on maritime connectivity and its definition and on the literature on the impact of trade costs and their components on trade. Its contribution is twofold. First it presents a revised version of the LSBCI which provides an overall view of maritime connectivity. ${ }^{1}$ Second, the impact of the revised LSBCI and of its components on bilateral exports of containerizable goods is assessed using a comprehensive set of country pairs observed for 8 years during the period 2006-2013.

The rest of the paper is organized as follows. Next section presents the data used for the construction of the LSBCI and the empirical exercise. Components of the proposed LSBCI section discusses the components of the revised version of the LSBCI and presents some descriptive statistics. Stylized facts of the revised LSBCI are commented in The LSBCI section. Empirical analysis section is dedicated to the assessment of the impact of the revised LSBCI and of its components on bilateral exports of containerizable goods. Concluding remarks section concludes.

\section{Data}

In order to identify the role of maritime connectivity on bilateral exports, our empirical assessment follows a two-step approach.

The first and most conspicuous step consists in constructing a revised version of the LSBCI. The underlying raw data is obtained from Lloyds List Intelligence (formally Containerisation International On-line) ("Lloyd's List Intelligence - Containers," n.d.). The dataset gives all the existing direct country pair connections and includes inter alia the number of ships sailing in this route, the TEU capacity of the largest vessel per direct route, the number of operators per route (both those who operate their own vessels and those who do not). The information is obtained annually, in the month of May. The data covers the reported deployment of all containerships at a given point in 
time. This methodology allows for comparisons over time, as the "sample" is always complete. UNCTAD started the systematic annual gathering of data in 2004 on the country level and in 2006 on the pair-of-country level. In addition to the LSBCI itself and its components which are defined and discussed in detail in next section, two novel variables are retrieved from this data: a variable indicating the number of transhipments necessary to connect any pair of countries and, the effective maritime distance to be covered between any pair of countries. Note that only in the case of a direct maritime connection, the effective (computed) maritime distance coincides with sea distance. Note also that information on the number of transhipments necessary to connect any pair of countries is symmetric: if two transhipments are necessary to move containers from country $\mathrm{C}$ to country $\mathrm{D}$, then the same number of transhipments is necessary to move containers in the opposite direction from D to C.

The second step consists in merging the above dataset with a set of gravity variables. Exports data is retrieved from UN COMTRADE, the reference international trade statistics database. Geography and policy variables are extracted from the CEPII gravity dataset as described in Mayer (2011). GDP data is taken from UNCTADstat database. Once merged these two datasets allow us to assess the impact of bilateral maritime connectivity. This is discussed in Empirical analysis section.

\section{Components of the proposed LSBCI}

The LSBCI is meant to reflect specifically the liner shipping connectivity between pairs of countries. In that context other aspects of connectivity such as distance are excluded. Distance between countries, and the level of overall connectivity of individual countries are of course also relevant for bilateral trade or trade costs. However, as regards the bilateral liner shipping connectivity as such, we aim at capturing this as a stand-alone factor.

With respect to the (Hoffmann et al. 2014) version of the LSBCI we replace the component reflecting the number of common connections that are reached with a single transhipment with the geometric mean of the number of direct connections for country in the pair. We are then proposing to include the following 5 components in the LSBCI: 1 ) the number of transhipments required to get from country $j$ to country $k ; 2$ ) the number of common direct connections; 3) the geometric mean of the number of direct connections each of the two countries; 4) the level of competition on services that connect country pairs; 5) the size of the largest ships on the weakest route.

The following sections briefly discuss the rationale for the inclusion of each component and present some stylized facts. The latter are based on a sample of 138 coastal countries (9453 country pairs) whose connectivity has been informed once a year during the period running from 2006 to 2013. The year 2007 is not reported due to unavailability of observations.

\section{Component \#1: the number of transhipments required to get from $\mathrm{j}$ to $\mathrm{k}$}

The first component of the proposed LSBCI is the theoretical minimum number of transhipments required to get from country $j$ to country $k$. As only a small part of all possible country pairs are directly connected with each other, the majority of country pairs require at least one transhipment in order to transport a container from one to 
the other. As can be seen form Table 1, in 2013 around 20\% of country pairs included in our sample were directly connected, $64 \%$ required at least one transhipment, $16 \%$ two transshipments. Figures for 2006 were 20, 67\% 12 respectively. In both years there were a few country pairs that required three transhipments. No country pairs require more than 3 transhipments - at least in theory. As each transhipment implies additional costs, time and risks of delays and damage, the LSBCI for a country-pair with a direct service will be higher than for a country-pair which is not connected through a direct service.

\section{Component \#2: the number of common direct connections}

The second component is the number of common direct connections between any two countries in each country pair. It is thus the total number of countries that have a direct connection to both, the origin country $j$ and the destination country $k$ in the pair. This is equivalent to the theoretical number of options a shipper has to get his goods shipped from $j$ to $k$ with one transhipment. The economic rationale for this component is twofold. First, countries that lie on the same coast (e.g., Chile, Peru, Ecuador) are served by the same services and consequently have far more connections (services that connect them) than they would have without their common services from/to e.g., Europe, North America or Asia. Empirically, it has been shown that countries that lie on the same ocean tend to trade more with each-other. Secondly, each common connection is one more option to trade via one transhipment. The more common connections I have (e.g., to get from Brazil to Ecuador via Panama, Jamaica or Bahamas), the better the two countries are connected and can trade with each-other. Table 2 reports a series a basic descriptive statistics for the seven years under investigation.

\section{Component \#3: the geometric mean of the number of direct connections}

We opted for the inclusion of a measure able to reflect the degree centrality of the country pair based on that of each composing country. The reason is twofold. First, the country pairs ranking obtained with the component initially proposed in (Hoffmann et al. 2014) appeared to be at odds with other components rankings. ${ }^{2}$ Second, despite the fact that this component is not bilateral in essence, the centrality of a country pair in the network of liner shipping connections is expected to be significantly affected by the centrality in that network of each country taken separately.

Moreover, we see this component as an indicator of the access to the network provided by each possible trade partner. In that context we could see the measure as bilateral. Taking the geometric mean provides a balanced measure of this bilateral access to the rest of the world. Basic descriptive statistics are reported in Table 3.

Table 1 Number of transhipments necessary to connect country pairs (shares in \%)

\begin{tabular}{lrrrrrrr}
\hline Number of Transhipments & 2006 & 2008 & 2009 & 2010 & 2011 & 2012 & 2013 \\
\hline 0 & 20.05 & 21.08 & 20.29 & 20.82 & 20.26 & 20.05 & 19.6 \\
1 & 66.98 & 67.25 & 64.2 & 64.43 & 63.65 & 64.49 & 64.23 \\
2 & 12.81 & 11.66 & 14.93 & 14.68 & 16.02 & 15.4 & 16.09 \\
3 & 0.16 & 0.01 & 0.58 & 0.06 & 0.07 & 0.06 & 0.07 \\
\hline
\end{tabular}

Note: Statistics are obtained for a sample of 138 coastal countries that is 9453 country pairs Source: Authors calculations, based on data from Lloyds List Intelligence 
Table 2 Number of common direct connections

\begin{tabular}{llllllll}
\hline Direct Connections (Common) & 2006 & 2008 & 2009 & 2010 & 2011 & 2012 & 2013 \\
\hline Median & 6 & 6 & 6 & 6 & 5 & 5 & 5 \\
Mean & 9 & 10 & 9 & 10 & 9 & 9 & 9 \\
Standard deviation & 10 & 11 & 10 & 11 & 11 & 11 & 11 \\
Maximum & 92 & 95 & 87 & 90 & 80 & 87 & 85 \\
\hline
\end{tabular}

Note: Statistics are obtained for a sample of 138 coastal countries that is 9453 yearly observations Source: Authors calculations, based on data from Lloyds List Intelligence

\section{Component \#4: the level of competition on services that connect country pairs}

The fourth component is the level of competition on services that connect country pairs. This is indicated with the constraining number of carriers that operate along the route between the country pair. The higher this number is, presumably the higher is the competition (Wilmsmeier and Hoffmann 2008). If the competition on a shipping route is increased, the shipping lines have an incentive to reduce their transportation costs and margins on these routes (Hummels et al. 2009) leading in turn to a decrease in transportation costs for shippers using that particular route.

In theory, making use of two or more transhipments, there are often hundreds of theoretical options to connect two countries. For the generation of this component, we have computed the Max-Min of the number of companies on the "best" connection between two countries in terms of the number of companies. For example, if I can get from $j$ to $k$ via $\mathrm{C}$ with 5 companies competing on the route $j-\mathrm{C}$ and 8 companies competing on the route $\mathrm{C}-k$, then the competition on the thinnest route for this option is 5 . If there is another option to get from $j$ to $k$ via $\mathrm{D}$, with 6 companies competing on the route $j$-D and 7 companies competing on the route D-k, then the competition on the thinnest route for this option is 6. Comparing these two options, the Max-Min (i.e., the highest number on the leg with the lowest number) is 6 , and " 6 " will be the value incorporated for the LSBCI for this component. Descriptive statistics are reported in Table 4.

\section{Component \#5: the size of the largest ships on the weakest route}

The fifth component is the size of the largest ship on the thinnest route. Calculations are based on the same approach used for the fourth component. The maximum ship size can be considered to be an indication of the level of infrastructure in the trading countries as well as the countries through which they tranship. The vessel size is also an indicator for economies of scale on the sea-leg.

It is interesting to note that in several connections where there is a direct link the ship deployed on the direct link is not the option with the largest ships. For example, direct services from the west coast of South America to Europe may deploy smaller

Table 3 Number of direct connections: Geometric mean

\begin{tabular}{llllllll}
\hline Direct Connections (Mean) & 2006 & 2008 & 2009 & 2010 & 2011 & 2012 & 2013 \\
\hline p50 & 23 & 24 & 23 & 23 & 24 & 24 & 23 \\
Mean & 25 & 27 & 26 & 26 & 27 & 27 & 26 \\
Sd & 15 & 16 & 15 & 15 & 15 & 15 & 15 \\
Max & 102 & 105 & 98 & 99 & 96 & 101 & 101 \\
\hline
\end{tabular}

Note: Statistics are obtained for a sample of 138 coastal countries that is 9453 country pairs Source: Authors calculations, based on data from Lloyds List Intelligence 
Table 4 Largest number of carriers operating on the least competitive leg

\begin{tabular}{llllllll}
\hline Carriers (Min-Max) & 2006 & 2008 & 2009 & 2010 & 2011 & 2012 & 2013 \\
\hline p50 & 3 & 3 & 3 & 2 & 3 & 4 & 4 \\
Mean & 4 & 4 & 4 & 4 & 4 & 5 & 5 \\
Sd & 5 & 5 & 4 & 4 & 4 & 5 & 5 \\
Max & 82 & 82 & 58 & 58 & 57 & 72 & 67 \\
\hline
\end{tabular}

Note: Statistics are obtained for a sample of 138 coastal countries that is 9453 country pairs Source: Authors calculations, based on data from Lloyds List Intelligence

ships than those deployed on services to Panama, and from Panama to Europe; put differently, for the LSBCI we will include a larger vessel size than the one from the direct service. Descriptive statistics are reported in Table 5.

\section{The LSBCI}

This section presents the procedure followed to construct our proposed LSBCI based on the components identified previously. It also discusses some properties and shows some general descriptive statistics.

\section{Components normalization and aggregation}

In order to establish a unit free index, all components are normalized using the standard formula Normalized_Value $=(\operatorname{Raw}-\operatorname{Min}(\operatorname{Raw})) /(\operatorname{Max}(\operatorname{Raw})-\operatorname{Min}(\operatorname{Raw}))$. We opted for this formula rather than the Raw/Max(Raw) formula essentially because of the existence of minimum values which differ from zero. If all minimum values for all components were zero both formulas would be equivalent and would generate identical normalized values.

The LSBCI is computed by taking the simple average of the five normalized components. As a consequence, the LSBCI can only take values between 0 and 1 . As to the first component, we simply take its complement to unity that is 1-Normalized_Value to respect the correspondence between higher values and stronger connectivity.

\section{Inter-temporal comparison}

In order to make index values comparable across time, maximum and minimum values for each component correspond to the maximum and minimum observed over the whole time period under consideration. The use of identical maximum and minimum values across years allows for a direct comparison across time and across countries. It is then possible to keep track of the evolution of a specific country-pair score across time but also in comparison with the evolution of other country-pairs' scores.

Table 6 reports some standards descriptive statistics characterizing the whole sample. Mean and median values show very little variation across time. Dispersion as measured

Table 5 Largest ship operating on the weakest leg

\begin{tabular}{llllllll}
\hline Ship_Size (Max-Min) & 2006 & 2008 & 2009 & 2010 & 2011 & 2012 & 2013 \\
\hline p50 & 1438 & 1550 & 1724 & 1713 & 1712 & 1700 & 1730 \\
Mean & 1853 & 2084 & 2473 & 2460 & 2525 & 2719 & 2817 \\
Sd & 1603 & 1797 & 2228 & 2315 & 2419 & 2785 & 2829 \\
Max & 9742 & 12,508 & 14,770 & 14,770 & 15,550 & 15,550 & 16,020 \\
\hline
\end{tabular}

Note: Statistics are obtained for a sample of 138 coastal countries that is 9453 country pairs Source: Authors calculations, based on data from Lloyds List Intelligence 
Table $6 \mathrm{LSBCl}$ : selected descriptive statistics

\begin{tabular}{lccc}
\hline Year & Mean & Median & Standard Deviation \\
\hline 2006 & 0.234 & 0.217 & 0.098 \\
2008 & 0.242 & 0.223 & 0.101 \\
2009 & 0.239 & 0.220 & 0.104 \\
2010 & 0.242 & 0.220 & 0.106 \\
2011 & 0.241 & 0.220 & 0.107 \\
2012 & 0.248 & 0.223 & 0.111 \\
2013 & 0.246 & 0.220 & 0.111 \\
\hline
\end{tabular}

Note: Statistics are obtained for a sample of 138 coastal countries that is 9453 country pairs

Source: Authors calculations

by the standard deviation increases slightly. The latter fact is reflected in the changes of the kernel probability density function shape observed between 2006 and 2013. The two functions are reported in the upper and lower panel of Fig. 1 respectively.

\section{Rankings}

The following tables report the top (Table 7) and bottom (Table 8) twenty country pairs according to the value of their LSBCI. Rankings are again based on our sample of 138 non landlocked countries corresponding to 9453 country pairs. Table 7 reveals that besides developed countries and essentially European countries only few Eastern Asian countries are part of the top 20 country pairs.

The bottom 20 country pairs are made up essentially of small and remote islands (e.g., Cook Islands Montserrat, Nairu), LDCs, and other countries such as Kuwait and Latvia, that are "remote" if considering their position within the global liner shipping network.

\section{LSBCl and components}

Table 9 reports some standard coefficients of correlation between the LSBCI and its components in their form. All coefficients are significant at $1 \%$. The negative sign on the first component is due to the fact that we consider the number of transshipments, meaning that more implies weaker connectivity. The strongest correlation is found for component 2, the number of direct common connections two countries share.

\section{$\mathrm{LSBCl}$ and trade}

Before undertaking a proper empirical analysis it is always informative to look at simple scatter plots showing the unconditional relationship between exports and the LSBCI. This relationship is shown in graph Fig. 2 for the years 2006, 2009 and 2013. A linear fit line is also reported. Its slope is a clear indication of the sign and "strength" of the relationship between exports and the LSBCI.

We observe that the relationship is definitely positive and its strength reflected by the slope of the linear fit has remained somewhat constant.

As to LSBCI components, pairwise correlation coefficients indicate a positive relationship between all components but the first one (number of transshipments) and exports. Moreover, coefficients are somewhat constant over the all period. Next section aims at testing the robustness of these results once conditionality related to the inclusion of additional core explanatory variables is accounted for. 


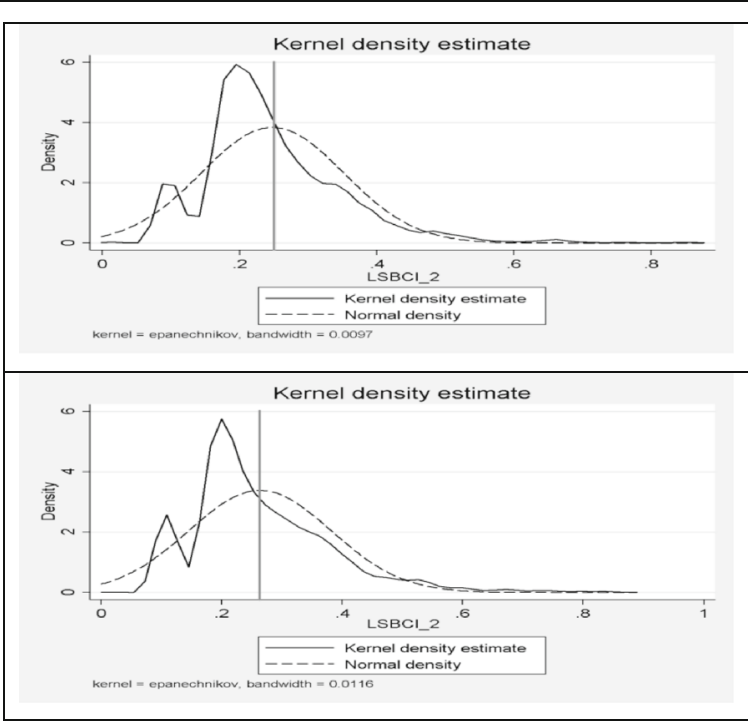

Fig. 1 LSBCI distribution (Kernel density estimation) in 2006 (upper panel) and 2013 (lower panel). Note: The vertical segment indicates the mean value. Source: Authors Calculations

Table 7 Top 20 country pairs in 2006 and 2013

\begin{tabular}{llllllll}
\hline Exporter & Importer & Year & LSBCl & Exporter & Importer & Year & LSBCI \\
\hline NLD & GBR & 2013 & 0.88 & GBR & BEL & 2006 & 0.87 \\
GBR & BEL & 2013 & 0.85 & NLD & GBR & 2006 & 0.86 \\
HKG & CHN & 2013 & 0.85 & DEU & BEL & 2006 & 0.85 \\
NLD & BEL & 2013 & 0.84 & GBR & DEU & 2006 & 0.84 \\
NLD & DEU & 2013 & 0.84 & NLD & BEL & 2006 & 0.84 \\
DEU & BEL & 2013 & 0.84 & NLD & DEU & 2006 & 0.82 \\
KOR & CHN & 2013 & 0.83 & FRA & BEL & 2006 & 0.80 \\
GBR & DEU & 2013 & 0.83 & GBR & FRA & 2006 & 0.79 \\
GBR & FRA & 2013 & 0.82 & HKG & CHN & 2006 & 0.78 \\
NLD & FRA & 2013 & 0.81 & FRA & ESP & 2006 & 0.76 \\
FRA & BEL & 2013 & 0.80 & NLD & FRA & 2006 & 0.76 \\
FRA & ESP & 2013 & 0.80 & FRA & DEU & 2006 & 0.75 \\
SGP & MYS & 2013 & 0.80 & ITA & FRA & 2006 & 0.73 \\
KOR & HKG & 2013 & 0.80 & GBR & ESP & 2006 & 0.72 \\
FRA & DEU & 2013 & 0.79 & ITA & ESP & 2006 & 0.72 \\
MYS & CHN & 2013 & 0.78 & SGP & MYS & 2006 & 0.71 \\
SGP & CHN & 2013 & 0.78 & ESP & BEL & 2006 & 0.71 \\
ITA & ESP & 2013 & 0.78 & NLD & ESP & 2006 & 0.71 \\
GBR & ESP & 2013 & 0.76 & KOR & CHN & 2006 & 0.71 \\
ESP & BEL & 2013 & 0.76 & ITA & GBR & 2006 & 0.70 \\
\hline SOure Aut & G & & & & &
\end{tabular}


Table 8 Bottom 20 in 2006 and 2013

\begin{tabular}{llllllll}
\hline Exporter & Importer & Year & LSBCl & Exporter & Importer & Year & LSBCI \\
\hline NRU & LVA & 2013 & 0.08 & MSR & MHL & 2006 & 0.02 \\
NRU & BGD & 2013 & 0.08 & YEM & MSR & 2006 & 0.02 \\
NRU & CYM & 2013 & 0.08 & COK & COD & 2006 & 0.01 \\
NRU & BRN & 2013 & 0.08 & SYC & MSR & 2006 & 0.01 \\
NRU & IRQ & 2013 & 0.08 & SVN & MSR & 2006 & 0.01 \\
NRU & KWT & 2013 & 0.08 & SOM & MSR & 2006 & 0.01 \\
NRU & COK & 2013 & 0.07 & MSR & COD & 2006 & 0.01 \\
QAT & NRU & 2013 & 0.07 & SDN & MSR & 2006 & 0.01 \\
NRU & MMR & 2013 & 0.07 & MSR & KHM & 2006 & 0.01 \\
COK & BGR & 2013 & 0.02 & PLW & MSR & 2006 & 0.01 \\
GEO & COK & 2013 & 0.02 & MSR & BGD & 2006 & 0.01 \\
SLE & COK & 2013 & 0.02 & MSR & MDV & 2006 & 0.01 \\
IRQ & COK & 2013 & 0.02 & MSR & BRN & 2006 & 0.01 \\
KWT & COK & 2013 & 0.02 & MSR & KWT & 2006 & 0.01 \\
COK & ALB & 2013 & 0.01 & MSR & IRQ & 2006 & 0.01 \\
COM & COK & 2013 & 0.01 & MSR & BHR & 2006 & 0.01 \\
QAT & COK & 2013 & 0.01 & MSR & COK & 2006 & 0.01 \\
LVA & COK & 2013 & 0.01 & MSR & MMR & 2006 & 0.01 \\
SOM & COK & 2013 & 0.01 & NRU & COD & 2006 & 0.01 \\
ERI & COK & 2013 & 0.01 & NRU & MSR & 2006 & 0.01 \\
\hline SOUF $: A u t$ & Calu & & & &
\end{tabular}

Source: Authors Calculations

\section{Empirical analysis}

This section presents results obtained by estimating an augmented version of the standard gravity model of bilateral exports that includes the LSBCI or its components. Even though we may not be able to talk clearly in causation terms our estimates provide a credible and unique assessment of the association between maritime connectivity and bilateral export of containerizable goods. The reference sample contains 138 coastal countries and corresponds to the reference sample used for the elaboration of descriptive statistics presented in previous sections.

The empirical strategy

Our focus being maritime connectivity, we take as our dependent variable exports in goods which are highly containerizable or its natural log depending on the estimated

Table 9 LSBCl and Components (raw): pairwise correlations in 2013

\begin{tabular}{lr}
\hline Component & \multicolumn{1}{c}{$\mathrm{LSBCl}$} \\
\hline 1 (number of transshipments) & -0.7878 \\
2 (common connections) & 0.9438 \\
3 (geometric average of each country's connections) & 0.9150 \\
4 (carriers) & 0.6049 \\
5 (largest ship size) & 0.7939 \\
\hline
\end{tabular}

Source: Authors Calculations 


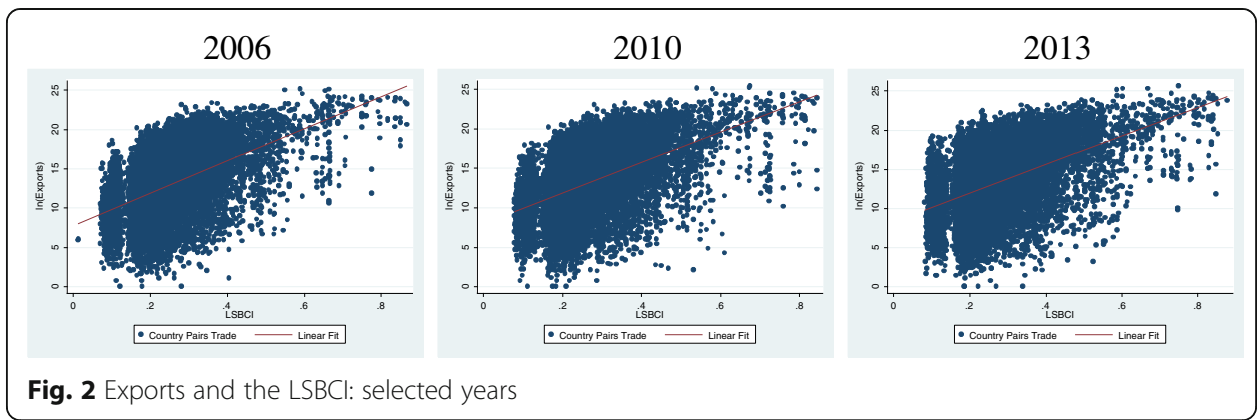

specification. As mentioned previously the volume of trade transported via sea represents about $80 \%$ of world trade volume. In this study our reference unit is not volume but value. We have that on average the value of trade that can be transported via sea has been increasing steadily from 50\% of total trade in 2006 to more than 56\% in 2013. Pairwise correlation between the series of total exports and exports which are highly containerizable is about 0.93 and is highly significant.

The motivation for using export values instead of volumes is twofold. First, the gravity equation, which is the workhorse econometric model of international trade, is about nominal trade not real trade or trade volume. ${ }^{3}$ Second, even if we wanted to work with trade volumes, defining the latter at the country level could be tricky. In most cases trade volumes are de facto nominal values deflated by some price indices, that is real values. And this takes us back to the first part of the motivation. Moreover, price deflator effects are systematically accounted for in our core econometric specification detailed below. As a consequence coefficient estimates identically apply to both nominal and real export variations.

Our reference empirical model is the standard gravity model of international trade augmented by the inclusion of our maritime connection variables. Our benchmark specification is given by,

$$
\ln \left(X_{j k t}\right)=o_{j t}+\delta_{k t}+\mathrm{Z}_{j k} \beta+\mathrm{T}_{j k t} \gamma+\varepsilon_{i j t}
$$

The dependent variable $\ln \left(X_{j k t}\right)$ is the natural logarithm of highly containerizable exports from country $j$ to country $k$ and recorded during year $t$. Variables $o_{j t}$ and $\delta_{k t}$ are exporter-and-time and importer-and-time specific intercepts. The inclusion of these sets of fixed effects should minimize the incidence of possibly omitted variables that are expected to be country-and-time-and-status (exporter or importer) specific. For instance, demand conditions prevailing at destination or supply capacity capability characterizing source countries are controlled for. Moreover, by construction these fixed effects also account for any time invariant country specific feature. For instance and importantly, the position of any country with respect to major maritime routes is likely to be accounted for by these sets of country fixed effects. $Z_{j k}$ is a vector of standard time invariant gravity bilateral variables. Namely it includes dummies for the existence of a common border (Border), a common language (Official_Lang), a common prevalent ethnic language (Official_Lang), a dummy indicating whether the trade partner was or was not a colony of the source country (Colony) and one indicating whether countries in the pair had a common colonizer post 1945 (Common_Col). $\mathrm{T}_{j k t}$ is a vector of variables reflecting bilateral and time varying trade costs. It includes the natural $\log$ of the effective maritime distance 
(LNSea_Dist) which corresponds to the shortest route linking country $\mathrm{j}$ to country $\mathrm{k}$. It also contains dummy (RTA) indicating whether the trade relationship is or is not preferential and dummy (Currency) indicating the existence of a common currency. The former dummy is expected to account for any possible impact of preferential trade agreements not only on tariff and non-tariff measures but also on transport costs. Remaining variables in $\mathrm{T}_{j k t}$ are bilateral connectivity index variables. We consider first the synthetic and normalized version of the LSBCI. We then consider both jointly and independently all components of the index namely the minimum number of transshipments to go form country $\mathrm{j}$ to country $\mathrm{k}$ (Transhipments), the number of common direct connections (Common_direct_C), the geometric mean of the number of direct connections of the country pair (Geom_Mean_Direct_C), the highest number of carriers operating on the leg with the lowest number of them (Carriers) and the size of the largest ship operating on the leg with the smallest ship (Largest_Ship_Size).

Gravity estimations are based on strictly positive exports flows. However, the presence of zeros in the matrix of bilateral trade relationships is a well-known fact. Our sample is no exemption. Zeros represent 38\% of export relationships in 2013.

In specification (1) zeros are de facto excluded from the estimation as the natural log is only determined for strictly positive values. Excluding zeros is expected to generate biased estimates. Several empirical approaches can be contemplated in order to explicitly account for the presence of zeros. However, as discussed for instance in Head and Mayer (2014) none of them can be expected to generate a zero bias in all circumstances. An always increasing number of papers opt for the Poisson Pseudo Maximum Likelihood estimator as the default estimator to deal with zeros as suggested by Santos Silva and Tenreyro (2006, 2011). The Poisson PML estimator implies some non-linearity in estimation and prevents us to include the full set of fixed effects included in the linear model. Only exporter and importer fixed effects together with period fixed effects are included. This, however, allows us to add time varying country specific variables such the natural log of GDP per capita in both the source and destination country that is LN_GDP_X and LN_GDP_M respectively.

\section{Results}

Table 10 reports estimated coefficients when maritime connectivity is represented by the LSBCI. Column (1) shows the results obtained with a standard OLS estimator and column (2) those obtain with the Poisson PML estimator. Usual gravity variable have the expected signs in both columns except for the colony and currency variables in column (2). The coefficient estimated for the LSBCI series is positive and highly significant in both estimations. With OLS this coefficient represents a semi-elasticityand indicates for instance that an increase of one standard deviation in the LSBCI computed over the whole period would be associated with an increase in the value of bilateral exports of $30 \%$ for the coastal countries sample. Coefficients obtained using a Poisson estimator cannot be interpreted as they are using an OLS estimator. They correspond to the variation in the logs of expected counts (the dependent variable), while holding the other variables in the model constant. As far as the LSBCI is concerned, its estimated coefficient suggest that an increase by one unit (equivalent to a variation of 0.01 ) of the index would translate into a variation in the logs of expected counts of 0.029 , than is an increase of exports by $3 \%$. This perfectly in line with estimates obtained with a standard OLS estimator. 
Table 10 Trade and LSBCI

\begin{tabular}{|c|c|c|}
\hline & $(1)$ & $(2)$ \\
\hline \multirow[t]{2}{*}{ LN_Sea_Dist } & $-1.185^{\mathrm{a}}$ & $-0.279^{\mathrm{a}}$ \\
\hline & $(0.0273)$ & $(0.0213)$ \\
\hline \multirow[t]{2}{*}{ Border } & $0.478^{\mathrm{b}}$ & $0.725^{\mathrm{a}}$ \\
\hline & $(0.186)$ & $(0.0700)$ \\
\hline \multirow[t]{2}{*}{ Official_Lang } & $1.028^{\mathrm{a}}$ & $0.407^{\mathrm{a}}$ \\
\hline & $(0.0865)$ & (0.0698) \\
\hline \multirow[t]{2}{*}{ Ethno_Lang } & 0.0459 & -0.0795 \\
\hline & $(0.0880)$ & $(0.0542)$ \\
\hline \multirow[t]{2}{*}{ Colony } & $0.820^{\mathrm{a}}$ & $-0.276^{\mathrm{a}}$ \\
\hline & $(0.143)$ & $(0.0624)$ \\
\hline \multirow[t]{2}{*}{ Common_Col } & $0.803^{\mathrm{a}}$ & $0.652^{\mathrm{a}}$ \\
\hline & $(0.0711)$ & $(0.0861)$ \\
\hline \multirow[t]{2}{*}{ RTA } & $0.745^{\mathrm{a}}$ & $0.405^{\mathrm{a}}$ \\
\hline & $(0.0509)$ & $(0.0454)$ \\
\hline \multirow[t]{2}{*}{ Currency } & 0.0497 & $-0.365^{\mathrm{a}}$ \\
\hline & $(0.211)$ & $(0.0914)$ \\
\hline \multirow[t]{2}{*}{$L S B C I$} & $3.123^{\mathrm{a}}$ & $0.029^{\mathrm{a}}$ \\
\hline & $(0.385)$ & $(0.211)$ \\
\hline \multirow[t]{2}{*}{ LN_GDP_X } & & $0.794^{\mathrm{a}}$ \\
\hline & & $(0.0137)$ \\
\hline \multirow[t]{2}{*}{ LN_GDP_M } & & $0.730^{\mathrm{a}}$ \\
\hline & & $(0.0225)$ \\
\hline Time period FE & Yes & Yes \\
\hline Exporter FE & - & Yes \\
\hline Importer FE & - & Yes \\
\hline Exporter-year FE & Yes & - \\
\hline Importer-year FE & Yes & - \\
\hline Observations & 89,043 & 138,328 \\
\hline$R^{2}$ & 0.789 & - \\
\hline Adjusted $R^{2}$ & 0.783 & - \\
\hline LL & & $-1.43191 e+14$ \\
\hline Chi_2 & & 18152.8 \\
\hline
\end{tabular}

Robust standard errors (clustered by country-pair) are in parentheses. ${ }^{\mathrm{a}} p<0.01,{ }^{\mathrm{b}} p<0.05$. Results reported in column (1) are obtained with the standard OLS estimator; the LN_Sea_Dist, LN_GDP_M and LN_GDP_X variables are in natural logs. Results reported in column (2) are obtained with a Poisson Pseudo Maximum Likelihood estimator Bold figures are coefficients' estimates

We then estimate the impact on bilateral exports of LSBCI components in their raw version. Results are reported in Table 11. Components are included both jointly (column(1)) and individually (columns (2) to (6)). Coefficients signs are consistent across specifications except for Geom_Mean_Direct_C. The latter coefficient is positive when estimated separately from other components coefficients and turns negative when estimated jointly. Precision in estimation is the highest when components are included jointly.

Not surprisingly, the number of transshipments affects negatively bilateral exports. Any additional transshipment would reduce by $40 \%$ the value of exports. The number of common direct connections is also positively related to bilateral exports. An 
Table $11 \mathrm{LSBCl}$ Components

\begin{tabular}{|c|c|c|c|c|c|c|c|}
\hline & (1) & (2) & (3) & (4) & (5) & (6) & (7) \\
\hline \multirow[t]{2}{*}{ LN_Sea_Dist } & $-1.017^{\mathrm{a}}$ & $-1.110^{\mathrm{a}}$ & $-1.213^{\mathrm{a}}$ & $-1.279^{\mathrm{a}}$ & $-1.280^{\mathrm{a}}$ & $-1.301^{\mathrm{a}}$ & $-1.306^{\mathrm{a}}$ \\
\hline & $(0.0306)$ & $(0.0288)$ & $(0.0271)$ & $(0.0274)$ & $(0.0272)$ & $(0.0264)$ & $(0.0272)$ \\
\hline \multirow[t]{2}{*}{ Border } & $0.560^{\mathrm{a}}$ & $0.541^{\mathrm{a}}$ & $0.513^{\mathrm{a}}$ & $0.536^{\mathrm{a}}$ & $0.543^{\mathrm{a}}$ & $0.614^{\mathrm{a}}$ & 0.276 \\
\hline & $(0.168)$ & $(0.172)$ & $(0.187)$ & $(0.185)$ & $(0.184)$ & $(0.176)$ & $(0.186)$ \\
\hline \multirow[t]{2}{*}{ Official_Lang } & $1.020^{\mathrm{a}}$ & $1.031^{\mathrm{a}}$ & $1.035^{\mathrm{a}}$ & $1.042^{\mathrm{a}}$ & $1.042^{\mathrm{a}}$ & $1.048^{\mathrm{a}}$ & $1.062^{\mathrm{a}}$ \\
\hline & $(0.0852)$ & $(0.0857)$ & $(0.0867)$ & $(0.0870)$ & $(0.0871)$ & $(0.0868)$ & $(0.0888)$ \\
\hline \multirow[t]{2}{*}{ Ethno_Lang } & 0.0257 & 0.0315 & 0.0432 & 0.0475 & 0.0481 & 0.0431 & 0.0344 \\
\hline & $(0.0866)$ & $(0.0871)$ & $(0.0882)$ & $(0.0886)$ & $(0.0887)$ & $(0.0884)$ & $(0.0900)$ \\
\hline \multirow[t]{2}{*}{ Colony } & $0.752^{\mathrm{a}}$ & $0.728^{\mathrm{a}}$ & $0.833^{\mathrm{a}}$ & $0.823^{\mathrm{a}}$ & $0.816^{\mathrm{a}}$ & $0.798^{\mathrm{a}}$ & $0.814^{\mathrm{a}}$ \\
\hline & $(0.134)$ & $(0.133)$ & $(0.144)$ & $(0.141)$ & $(0.140)$ & $(0.137)$ & $(0.140)$ \\
\hline \multirow[t]{2}{*}{ Common_Col } & $0.766^{\mathrm{a}}$ & $0.764^{\mathrm{a}}$ & $0.820^{\mathrm{a}}$ & $0.827^{\mathrm{a}}$ & $0.828^{\mathrm{a}}$ & $0.823^{\mathrm{a}}$ & $0.757^{\mathrm{a}}$ \\
\hline & $(0.0698)$ & $(0.0699)$ & $(0.0709)$ & $(0.0710)$ & $(0.0710)$ & $(0.0705)$ & $(0.0713)$ \\
\hline \multirow[t]{2}{*}{ RTA } & $0.726^{\mathrm{a}}$ & $0.718^{\mathrm{a}}$ & $0.752^{\mathrm{a}}$ & $0.757^{\mathrm{a}}$ & $0.757^{\mathrm{a}}$ & $0.761^{\mathrm{a}}$ & $0.691^{\mathrm{a}}$ \\
\hline & $(0.0495)$ & $(0.0495)$ & $(0.0510)$ & $(0.0510)$ & (0.0509) & $(0.0505)$ & $(0.0509)$ \\
\hline \multirow[t]{2}{*}{ Currency } & 0.151 & 0.275 & 0.0476 & 0.160 & 0.195 & 0.305 & 0.206 \\
\hline & $(0.187)$ & $(0.188)$ & $(0.212)$ & $(0.205)$ & $(0.203)$ & $(0.187)$ & $(0.207)$ \\
\hline \multirow[t]{2}{*}{ Transhipments } & $-0.400^{\mathrm{a}}$ & $-0.564^{\mathrm{a}}$ & & & & & \\
\hline & $(0.0440)$ & $(0.0374)$ & & & & & \\
\hline \multirow[t]{2}{*}{ Common_direct_C } & $0.0474^{a}$ & & $0.0195^{\mathrm{a}}$ & & & & \\
\hline & $(0.00494)$ & & $(0.00303)$ & & & & \\
\hline \multirow[t]{2}{*}{ Geom_Mean_Direct_C } & $-0.0444^{a}$ & & & $0.00810^{b}$ & & & \\
\hline & $(0.00629)$ & & & $(0.00366)$ & & & \\
\hline \multirow[t]{2}{*}{ Largest_Ship_Size } & $0.0161^{b}$ & & & & -0.00172 & & \\
\hline & $(0.00781)$ & & & & $(0.00783)$ & & \\
\hline \multirow[t]{2}{*}{ Carriers } & $-0.0187^{\mathrm{a}}$ & & & & & $-0.0206^{\mathrm{a}}$ & \\
\hline & $(0.00535)$ & & & & & $(0.00429)$ & \\
\hline Time period FE & Yes & Yes & Yes & Yes & Yes & Yes & Yes \\
\hline Exporter-year FE & Yes & Yes & Yes & Yes & Yes & Yes & Yes \\
\hline Importer-year FE & Yes & Yes & Yes & Yes & Yes & Yes & Yes \\
\hline Observations & 89,043 & 89,043 & 89,043 & 89,043 & 89,043 & 89,043 & 89,043 \\
\hline$R^{2}$ & 0.791 & 0.790 & 0.789 & 0.788 & 0.788 & 0.788 & 0.789 \\
\hline Adjusted $R^{2}$ & 0.785 & 0.784 & 0.783 & 0.782 & 0.782 & 0.783 & 0.784 \\
\hline
\end{tabular}

additional common direct destination is associated with about $5 \%$ higher value of bilateral exports. An increase by 1000 TEU (unit of reference of the Largest_Ship_Size variable) of the largest ship operating on any leg of a maritime route is associated with an increase in the value of bilateral exports of $1 \%$.

The interpretation of the sign obtained for the geometric mean of direct connections variable and the smallest number of carriers operating on any leg of a maritime route variable is not necessarily intuitive. Both variables are found to be negatively related to bilateral exports in the joint components estimation. As mentioned previously the Geom_Mean_Direct_C variable is found to affect positively bilateral exports when its impact is 
assessed separately from other components. The switch in sign when estimated jointly may be the consequence of the very high correlation existing between the latter variable and the Common_direct_C variable rather than an economic mechanism strictly speaking. However, if the latter variable is removed from the joint estimation then the Geom_Mean_Direct_C does enter positively in the estimation but its effect loses significance. Both variables are a reflection of the country pair in the network of maritime connections. However, while the Common_direct_C variable is a proper bilateral variable capturing the true degree of interconnectivity between the two countries, the Geom_Mean_Direct_C is bilateral only by construction and may instead capture the degree of diversification of each country forming the pair in the maritime network. This could explain both the opposite signed observed when these two variables are included in the same specification and the fact that the coefficient of Geom_Mean_Direct_C is not precisely estimated when included alone with the remaining three LSBCI components. The negative sign observed for the coefficient of Carriers could also be problematic in interpreting. We expect a larger number of companies operating on any leg of a maritime route to be synonymous of more competition on the market of maritime services and eventually in lower freight costs. Data used for bilateral exports are in cif units meaning that any change in the cost of freight is directly transmitted to exports values. This possibly direct pass-through effect may dominate any demand side effect that could lead to an increase in the value of exports. Indeed the relative change in the value of exports is equal to the relative change in the quantity exported plus the relative change in price. The relative change in quantity cannot be unequivocally estimated for aggregate export data as it is necessary to determine a common unit to significantly different quantities. If we take the quantity effect to be close to zero due to some lags in the reaction of the demand to changes in prices, the estimated coefficient can be seen as a pure price effect. The obtained sign would then be consistent with expectations about the relationship between competition amongst shipping companies and the cost of freight. The estimate could then be interpreted to suggest that adding one carrier on the least competitive leg of a maritime route would decrease the cost of freight by about $2 \%$. Results (not reported) obtained by implementing a Poisson estimator are similar both qualitatively and quantitatively for all variables except once again the Colony and the Currency ones.

Column (7) of Table 11 reports the results obtained without including any of our maritime connectivity variables. The most striking result if we compare with those reported in column (1) of Table 10 and column (1) of Table 11 is the statistically significant difference between estimates of the effective maritime distance effects. Not including maritime connectivity variables may generate an overestimated impact of the latter. If we look at results obtained for each component taken individually the difference is even larger for the number of transhipments respective variable that is component 1 . In other words, standard gravity results may suffer from some omitted variable bias if connectivity related variables are not included. What is true for trade in containerized goods is most likely to be true for all types of goods.

\section{Limitations and robustness checks}

As mentioned previously, above results should not be interpreted as representative of causal relationships strictly speaking. Our empirical set up suffers from several constraints. 
We tried to remove at least partially some of them and tested the robustness of our core results.

\section{Reverse causation}

It could be reasonable to expect some reverse causation to be at work. Maritime connectivity does influence trade flows and this is confirmed by our findings. However, trade flows could also influence maritime connectivity and its components. This could be particularly true for components 4 and 5 . The size of the largest ship operating on a given route may react to the intensity of trade observed on that route. Service providers may adapt their supply to the demand they perceive. The same reasoning could apply to the number of carriers which active on any given route. In order to check the robustness of results reported in Tables 10 and 11 we estimated all specifications using lag values ( 1 and 2 periods) of the LSBCI and its components. Most results hold. Moreover the Largest_Ship_Size coefficient becomes significant and positive when introduced individually.

\section{Multicollinearity}

Multicollinearity exists whenever two or more of the predictors in a regression model are moderately or highly correlated. This is clearly the case of some of our LSBCI components. For instance the coefficient of correlation between component 2 (number of common direct connections) and component 3 (geometric mean of direct connections) is close to 0.9 over the whole period of investigation. This may be seen as a case of structural multicollinearity as both components are constructed from the same source of information. Both components are also strongly correlation to component 4 (size of the largest ship). As mentioned previously this may affect our results and this is what we suspected for the estimated coefficient of component 4. However, expect for being cautions in interpreting our results very little can be done to get rid of multicollinearity. We adopted the approach known as "centering the predictors". Centering a predictor merely entails subtracting the mean of the predictor values in the data set from each predictor value. We applied this transformation to all LSBCI components. Results hold in general and may be seen as more satisfactory as component 4's estimated coefficient is now not significantly different form zero in what would correspond to column (1) of Table 11 specification and keeps its positive sign when estimated separately.

\section{Distances, air and land transport connectivity, trade facilitation, and additional variables}

A complete "gravity" model of international trade will need to incorporate all possible modes of transport, as well as the applicable air, maritime and over-land distances. The more comprehensive the data set is, the better specific variables for example on trade facilitation and transport infrastructure as well as policy implications can be analysed. This goes beyond the scope of this paper. However, it may be argued that part of the trade considered here may have been moved by air cargo rather than by sea cargo. This could be an issue indeed. However, air cargo transported trade remains limited compared to sea cargo transported trade. Moreover, it is extremely difficult to obtained precise information about the mode of transport used. Such information does exist at the firm and product level but is usually undiscovered in public statistics. 


\section{Concluding remarks}

The main objective of this paper was to provide an empirical assessment of the effects of maritime connectivity on bilateral exports using an original index of bilateral liner shipping connectivity. Some precise estimation of the respective role of connectivity components has also been produced. As has been shown, improving transport connectivity can be an important facilitating aspect of bilateral trade. For instance, any additional transshipment is associated with a value of exports lower by $40 \%$. An additional common direct destination is associated with about $5 \%$ higher value of bilateral exports. An increase by 1000 TEU (unit of reference of the Largest_Ship_Size variable) of the largest ship operating on any leg of a maritime route is associated with an increase in the value of bilateral exports of $1 \%$. Results can certainly be considered encouraging despite the existence of some possibly constraining factors. However, there is scope for further work on the individual components and the interpretation of the empirical results.

There is also scope for integrating land-locked countries in our reference sample of coastal countries. Land-locked countries also trade overseas, albeit making use of seaports of neighboring transit countries. By assigning the maritime connectivity of transit countries to the trade of land-locked countries, we should be able to generate a refined figure of the impact of maritime connectivity that could be made group specific. We could also take into account trade logistics indicators such as the World Bank's Logistics Performance Index (LPI) of both, the land-locked and the transit countries.

The newly developed LSBCI (Liner Shipping Bilateral Connectivity Index) used in this paper proves to be a reliable indicator of maritime connectivity as far as trade in containerizable goods is concerned. Moreover, results suggest that the omission of connectivity indicator of that kind could lead to overestimate the impact of bilateral maritime distance.

A interesting path for future research relies on the possibility to clearly distinguish between modes of transport used for all trade transactions. This would allow for a precise identification of the impact of connectivity per mode: air, sea and road. Although this type of information remains hardly accessible firm level data collected by customs is a promising direction to be followed.

\section{Endnotes}

${ }^{1}$ This version of the LSBCI is publicly available at http://unctadstat.unctad.org/EN/.

${ }^{2}$ Possibly there was a conceptual error due to the complementarity with the second component. Also, conceptually, the component did not add any fundamental additional aspect of connectivity to the composite index, as compared to the second component.

${ }^{3}$ See Baldwin and Taglioni (2007) for an extensive discussion.

Authors' contributions

We further declare that each author has equally contributed to the writing of this article and its revision. Both authors read and approved the final manuscript.

Competing interests

The authors declare that they have no competing interests.

Author details

'Division on International Trade, UNCTAD, Palais des Nations, Geneva, Switzerland. ${ }^{2}$ Division on Technology and Logistics, UNCTAD, Palais des Nations, Geneva, Switzerland. 


\section{References}

Anderson JE, van Wincoop E (2003) Gravity with gravitas: a solution to the border puzzle. Am Econ Rev 93:170-192 Angeloudis P, Bichou K, Bell M, Fisk D (2006) Security and reliability of the liner container shipping network: Analysis of robustness using a complex network framework, presented to IAME 2006 conference, Melbourne

Arvis J-F, Shepherd B, Reis JG, Duval Y, Utoktham C (2013) Trade costs and development: a new data set. World Bank - Economic Premise, p 1-4

Asturias J, Petty S (2012) A model of trade with endogenous transportation costs

Baldwin R, Taglioni D (2007) Trade effects of the euro: a comparison of estimators. J Econ Interac 22(4):780-818

Bernhofen DM, El-Sahli Z, Kneller R (2013) Estimating the effects of the container revolution on world trade (No. 4136), CESifo Working Papers. CESifo, Center for Economic Studies and Ifo Institute

Bichou K (2004) The ISPS Code and the cost of port compliance: an initial logistics and supply chain framework for port security assessment and management, Maritime Economics and Logistics, 6, 322-348

Clark X, Dollar D, Micco A (2004) Port efficiency, maritime transport costs and bilateral trade. J Dev Econ 75(2):417-450

Fugazza M (2015) Maritime connectivity and trade. Policy issues in international trade and commodities, study series no. 70.

Fugazza M, Hoffmann J, Razafinombana R (2013) Building a dataset for bilateral maritime connectivity. Région et Développement 41:101-124

Head K, Mayer T (2014) Gravity equations: toolkit, cookbook, workhorse. Handbook of International Economics, Vol. 4. 545 Q14 Gopinath, Helpman, and Rogoff, eds. Elsevier.

Helble M (2014) The Pacific's connectivity and its trade implications. ADBI working paper 499. Asian Development Bank Institute, Tokyo

Hoffmann J, Van Hoogenhuizen J-W, Wilmsmeier G (2014) Developing an index for bilateral liner shipping connectivity. In: IAME 2014 Conference Proceedings. Presented at the International Association of Maritime Economists (IAME), Norfolk, United States

Hummels D, Lugovskyy V, Skiba A (2009) The trade reducing effects of market power in international shipping J Dev Econ 89:84-97

Kosowska-Stamirowska Z, Ducruet C, Rai N (2016) Evolving structure of the maritime trade network: evidence from the Lloyd's Shipping Index (1890-2000). Journal of Shipping and Trade 1:10

Kumar S, Hoffmann J (2002) Globalization, the maritime nexus, in Handbook of Maritime Economics and Business, edited by Grammenos, C., London: LLP, 35-62

Márquez Ramos L, Martínez Zarzoso I, Pérez García E, Wilmsmeier G (2007) Transporte Marítimo: Costes de Transporte y Conectividad en el Comercio Exterior español. In Lecciones de Economía Marítima. La Coruña. Spain. ISBN: 978-84-9745-052-3

Mayer T, Zignago S (2011) Notes on CEPII's distances measures : the GeoDist Database. CEPII Working Paper 2011-25

McCalla Robert J, Brian Slack, Claud Comtois (2005) The Caribbean basin: Adjusting to global trends in containerization, in Maritime Policy and Management, VOL. 32, NO. 3, 245-261

Notteboom T (2006a) The Time Factor in Liner Shipping Services, in: Maritime Economics and Logistics, 8, 19-39

Notteboom T (2006b) Traffic inequality in seaport systems revisited, in: Journal of transport geography, 14:2 (2006): 95-108

Sánchez RJ, Hoffmann J, Micco A, Pizzolitto GV, Squt M, Wilmsmeier G (2003) Port efficiency and international trade: port efficiency as a determinant of maritime transport costs. Maritime Economics \& Logistics 5:199-218. doi:10.1057/palgrave.mel.9100073

Santos Silva JMC, Tenreyro S (2006) The log of gravity. Rev Econ Stat 88(4):641-658

Santos Silva JMC, Tenreyro S (2011) Further simulation evidence on the performance of the Poisson pseudo-maximum likelihood estimator. Econ Lett 112(2):220-222

UNCTAD (2008) The modal split of international goods transport. Transport Newsletter, UNCTAD/SDTE/TLB/MISC/2008/1.

UNCTAD (2014) Review of maritime transport 2014. United Nations, New York, Geneva

UNCTAD STAT, n.d. Liner Shipping Connectivity Index (LSCI) [WWW Document]. Liner Shipping Connectivity Index (LSCl). URL http://unctadstat.unctad.org/wds/TableViewer/tableView.aspx?Reportld=92 (accessed 19 Apr 2015)

Wilmsmeier G (2014) International maritime transport costs: market structures and network configurations, transport and society. Ashgate Publishing Company, Burlington

Wilmsmeier G, Martínez-Zarzoso I, (2010) Determinants of maritime transport costs - a panel data analysis for Latin American trade, Transportation Planning and Technology, Taylor \& Francis Journals, vol. 33(1), pages 105121-1051

Wilmsmeier G, Hoffmann J (2008) Liner shipping connectivity and port infrastructure as determinants of freight rates in the Caribbean. Maritime Economics \& Logistics 10:130-151. doi:10.1057/palgrave.mel.9100195

Wilmsmeier G, Hoffmann J, Sánchez RJ (2006) The impact of port characteristics on international maritime transport costs. In Research in Transportation Economics Volume 16: Port Economics. edited by : K. Cullinane and W. Talley, Amsterdam: Elsevier, 117-42 